This item was submitted to Loughborough's Research Repository by the author.

Items in Figshare are protected by copyright, with all rights reserved, unless otherwise indicated.

\title{
A mathematical model for airflow and heat transfer through fibrous webs
}

PLEASE CITE THE PUBLISHED VERSION

PUBLISHER

Professional Engineering Publishing / @ IMECHE

VERSION

VoR (Version of Record)

LICENCE

CC BY-NC-ND 4.0

\section{REPOSITORY RECORD}

Hossain, Mamdud, Memis Acar, and W. Malalasekera. 2019. "A Mathematical Model for Airflow and Heat Transfer Through Fibrous Webs”. figshare. https://hdl.handle.net/2134/4535. 
This item was submitted to Loughborough's Institutional Repository (https://dspace.lboro.ac.uk/) by the author and is made available under the following Creative Commons Licence conditions.

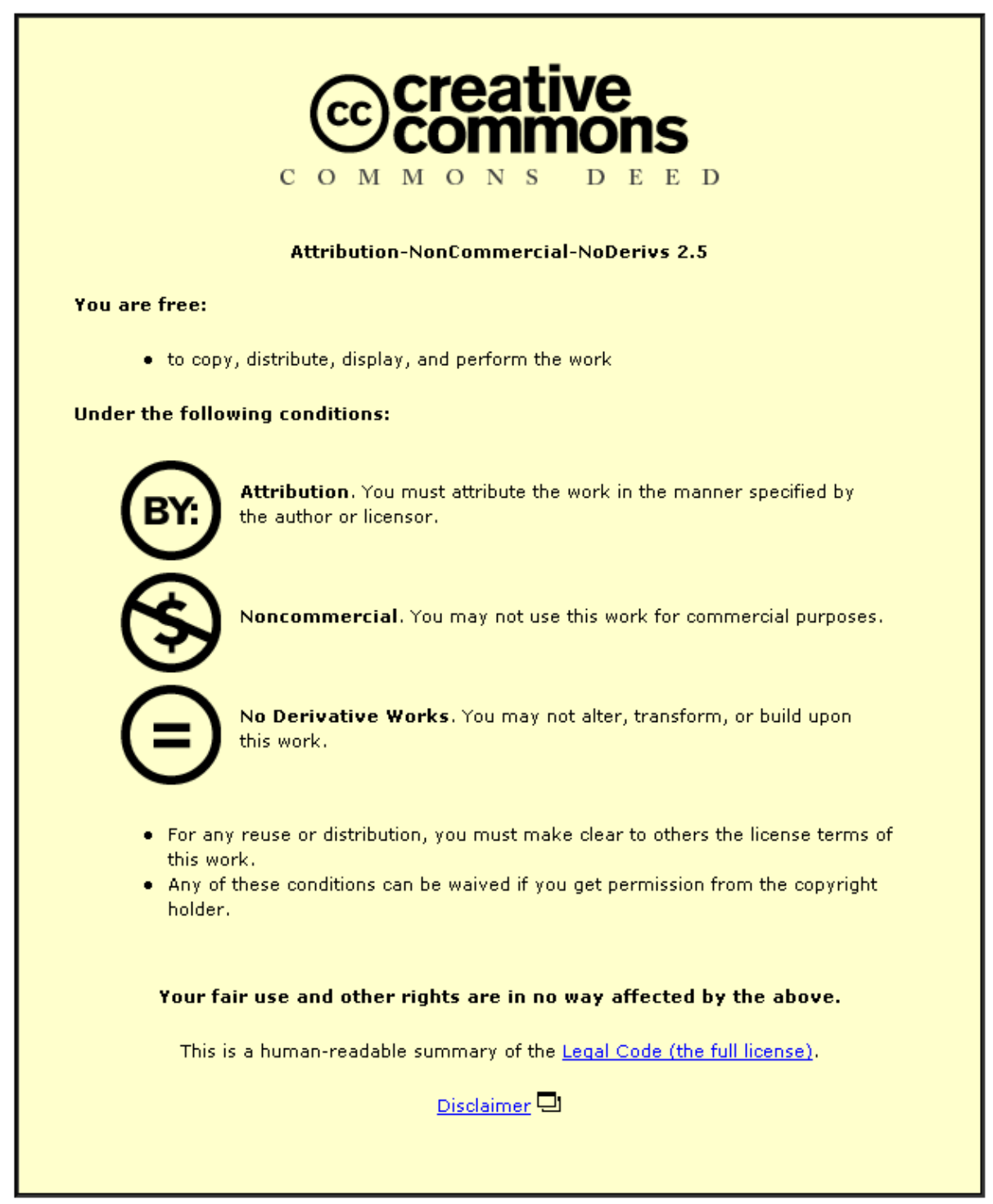

For the full text of this licence, please go to: http://creativecommons.org/licenses/by-nc-nd/2.5/ 


\title{
A mathematical model for airflow and heat transfer through fibrous webs
}

\author{
M Hossain, M Acar*, and W Malalasekera
}

Mechanical and Manufacturing Engineering, Loughborough University, Leicestershire, UK

The manuscript was received on 15 June 2004 and was accepted after revision for publication on 19 May 2005.

DOI: $10.1243 / 095440805 X 33199$

\begin{abstract}
A mathematical model based on computational fluid dynamics has been developed to investigate the airflow and heat transfer through fibrous webs. The model is based on the porous media concept and involves solving equations for continuity, momentum, and energy. A thermal energy equation is developed, which incorporates the heat of fusion of fibres in the fibrous web. Local flow information such as air velocity, temperature, and melt fraction of fibres is obtained from the simulations. An important outcome of the simulation is the prediction of time required to melt fibres in the web under different working conditions. This information can be used potentially in the design of through-air bonding process for nonwovens manufacturer.
\end{abstract}

Keywords: cfd, nonwoven, through-air bonding, porous

\section{INTRODUCTION}

Use of nonwovens in a variety of disposable and durable end-use products, including hygiene, filtration, bedding, furniture, carpet backings, and wipes, is growing tremendously. Nonwovens are made of directionally or randomly distributed fibres and are bonded together by friction, cohesion, or adhesion. Nonwovens are generally produced in three stages: (a) web formation, (b) web bonding, and (c) finishing treatment. Nonwoven manufacture starts by the arrangement of fibres in a web. The fibres can be staple fibres packed in bales or filaments extruded from molten polymer granules. Nonwovens web can be formed by a number of different techniques, including carding, spunbonding, melt blowing, air laying, and wet laying. Nonwoven webs have little strength in their unbonded form and must therefore be consolidated. The fibres in the web are bonded together using different processes such as needle punching, hydroentangling, chemical bonding, and thermal bonding.

\footnotetext{
*Corresponding author: Department of Mechanical and Manufacturing Engineering, Loughborough University, Leicestershire LU11 3TU, UK.
}

The thermal bonding of nonwovens can be categorized into two main groups: conductive heat bonding and convective heat bonding. Conductive heat bonding of nonwovens, such as hot calendaring, has become well established owing to the advantages of reduced energy requirements, higher speeds, cleanliness, space savings, improved product properties, and versatility. In parallel to industrial developments, significant research efforts have been directed to the conductive thermal bonding techniques, which have led to a better understanding of the process, the structure of the bonded fabric, the bonding mechanisms, and failure modes and in turn to improved processes [1-3].

The convective through-air bonding process, the subject of the current research, involves wrapping a nonwoven web around a perforated drum and passing hot air through the web to heat and bond the web. Figure 1 shows a schematic drawing of a through-air bonding system. Most throughair-bonded webs consist of bicomponent fibres. The high melting point core fibres provide structural rigidity of the web and the low melting point sheath fibres easily melt and bond the fibres together. The control of air temperate, flow distribution, and heat transfer to the web is very important for the throughair bonding process. However, the through-air bonding process, despite its importance, has not received the 


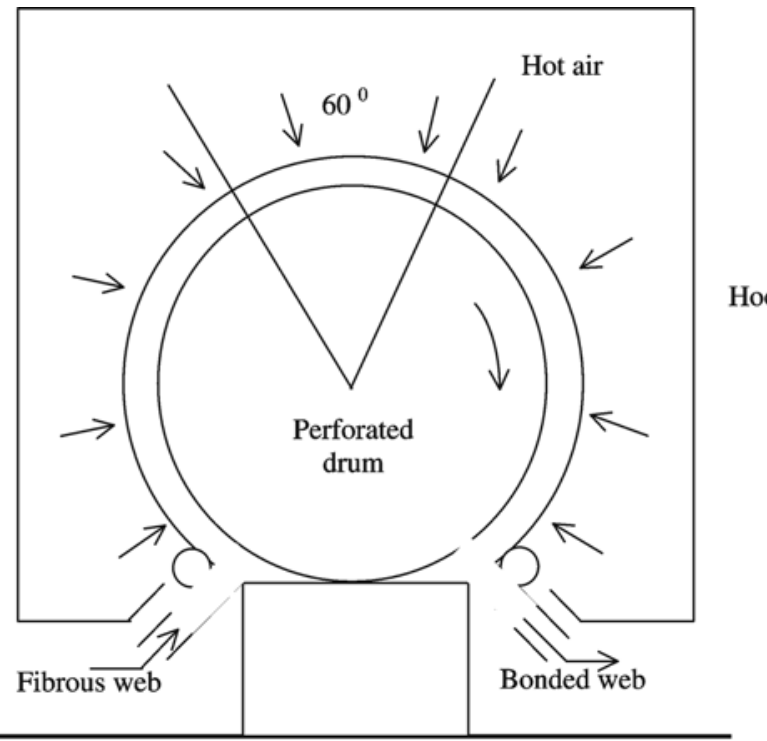

Fig. 1 Schematic drawing of the through-air bonding system

level of attention from researchers that conductive bonding processes enjoyed.

The present study seeks to provide a numerical model using computational fluid dynamics (CFD) that will provide a better understanding of the airflow and heat transfer through a nonwoven web. The model is based on the solution of continuity, momentum, and energy equations along with equations for turbulence in a porous media. The porous media model of the commercial CFD code FLUENT was utilized for the numerical calculations. Though the FLUENT software provides many builtin capabilities, it does not offer all of the physical models required to address the complex processes that occur in the through-air bonding process. For example, FLUENT's default thermal energy equation in porous media does not consider melting of the porous matrix itself. Therefore, a new thermal energy equation is developed to take into account the heat of melting of fibres. The effect of porosity, airflow velocity, and web thickness on the heating and melting of the fibres are investigated and reported here.

\section{LITERATURE SURVEY}

The literature survey in the area of the through-air bonding process revealed that published research work mostly relates to experimental and empirical studies of different process parameters and their effects on the physical and mechanical properties of nonwovens rather than the fundamental mechanism and modelling of through-air bonding of nonwoven fabrics. Randall [4] investigated the effect of process variables such as supply air temperature, through-air velocity, dwell time in heat zone, and restraining and carrying wire mesh sizes on the mechanical properties of nonwoven web produced by the through-air bonding. In addition, Randall [5] investigated the effect of fibre content on the properties of the bonded web using a blend of single binder fibre and single matrix fibre. He varied the air temperature delivered to the web, binder fibre content, binder fibre type, and product basis weight, holding the line speed and through-air velocity constant.

There are more publications on the through-air drying process $[\mathbf{6}-\mathbf{1 3}]$, which is of significant relevance to the research in the through-air bonding process. Similar machines are used in both processes [6]. However, the through-air bonding process has the added complication of heating the fibres to soften, melt, and bond. With the advent of the honeycomb style drums, the through-air bonding process gained a new impetus. Watzl and Rückert [6] have reported basic principles of the through-air drying process, which has a 50-year history. Poirier et al. [7] and Tourigny and Ramaswamy [8] reported methods of analysing the hood drying rates in drying permeable tissue and towel products on the basis of two independent methods, namely, the hood heat balance method and the system energy balance method. There appears to be a good correlation between the predictions of these two methods and between the predictions and the actual drying rate. Cui et al. [9] established the empirical relationships on the basis of theoretical modelling and experimental data that simulates the through-air drying of air permeable products. Ramaswamy and Holm $[10,11]$ reported mathematical modelling and experimental verification of high intensity drying of paper and board. More recently, Lee et al. [12] reported an experimental study of through-air drying of unbacked tufted carpets using a pilot-scale laboratory dryer and magnetic resonance imaging (MRI) to study the effect of the vacuum extraction procedure on the moisture distribution and profiles. Lee et al. [13] also reported a transient mathematical model to simulate the through-air drying process for tufted textile materials, which provides predictions that closely agree with experimental results.

The CFD techniques have been tremendously improved in the last decade and have been extensively used in design of aircrafts, automotives, aeroacoustics, combustion research, and in many engineering applications [14]. However, the use of CFD is relatively recent in textile research and in industry, where the application of fluids plays a significant role. The control of fluid flow that affects the fibres, yarns, and fabrics is very important in textile processes in general and in nonwoven processes 
in particular. Gong et al. [15] used the FLUENT CFD code to develop a process for manufacturing threedimensional web structures. Gong et al. [16] in a follow up article investigated the distribution of velocity, pressure, and temperature distribution inside the through-air bonding chamber. Kim et al. [17] have reported a computational analysis of the thermal bonding behaviour of bicomponent fibres. Tafreshi and Pourdeyhimi [18] reported a CFD study of flow dynamics in hydroentangling nozzles. Tafreshi et al. [19] reported a numerical study of the effects of orifice configuration on the water jet properties in the hydroentangling cone-up and cone-down geometries. Mao and Goswami [20] have described a mathematical model to predict the bonding behaviour of nonwovens in the ultrasonic bonding method using a finite element method.

\section{MODELLING APPROACH}

\subsection{Mathematical formulation}

The complicated interfacial geometry of the porous matrix (fibrous web) and airflow prohibits the solution of the microscopic conservation equations for mass, momentum, and energy. Therefore, a macroscopic formulation based on volume averaging is used in the present study. In this approach, a conservation equation valid for each phase is integrated over a small volume element $V$. As shown in Fig. 2, such a volume element is composed of air of volume fraction $\phi$ (porosity) and fibres of volume fraction $(1-\phi)$. The fibres are bicomponent with a sheath of volume fraction of $\varepsilon$ of the fibres volume (i.e. $\varepsilon(1-\phi)$ of the total volume) and a core of volume fraction $(1-\varepsilon)$ of the fibre volume (i.e.

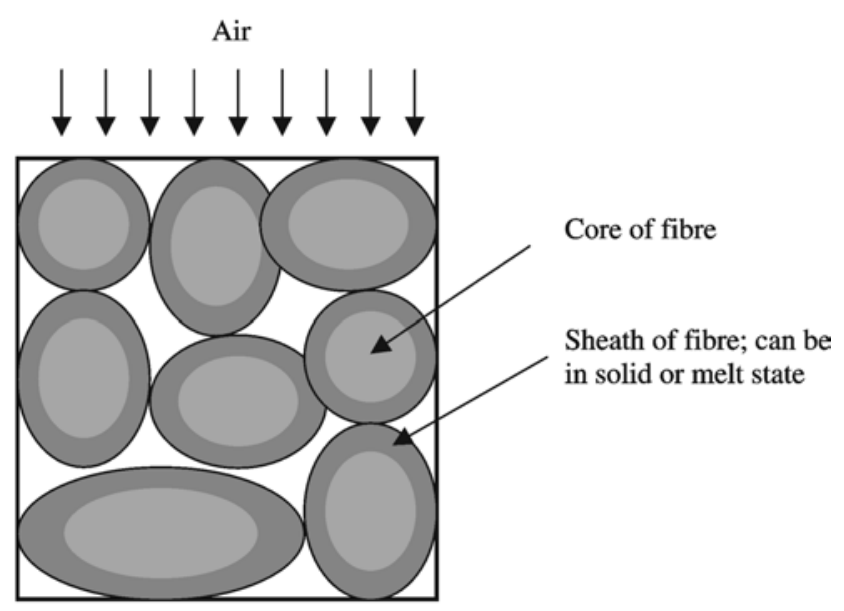

Fig. 2 Volume element of a two-dimensional nonwoven web made of bicomponent fibres $(1-\varepsilon)(1-\phi)$ of the total volume). Te sheath fibre can be in solid or melt state during the melting process. The fraction of melt in sheath fibre is given by $\gamma$; the sheath fibre will be in complete melt state if $\gamma=1$ and will be in solid state if $\gamma=0$.

The following assumptions are made for simplicity.

1. The thermophysical properties of the air as well as fibres are homogeneous and isotropic.

2. The porous matrix and the flowing air are in thermal equilibrium, i.e. the temperature of air and fibre phase within a control volume has same values.

3. The density change due to solid-liquid phase change is negligible.

4. Fibres both in solid and in liquid states are rigid, so there is no change of porosity and permeability during heating and melting.

On the basis of assumptions, the averaged mass and momentum equations for a single domain-based model are given by Beckermann and Viskanta [21].

\section{Continuity}

$$
\frac{\partial\left(\phi \rho_{\mathrm{a}}\right)}{\partial t}+\nabla\left(\rho_{\mathrm{a}} \bar{u} \phi\right)=0
$$

\section{Momentum}

$$
\rho_{\mathrm{a}} \frac{\partial(\phi \bar{u})}{\partial t}+\rho_{\mathrm{a}}(\phi \bar{u} \cdot \nabla) \bar{u}=-\phi \nabla P+\mu \nabla^{2}(\phi \bar{u})-\frac{\mu}{k} \bar{u}
$$

where $\rho_{\mathrm{a}}$ is the density of air, $\phi$ the porosity, and $k$ the permeability of the air. The last term in the momentum equation is due to the Dercy's term representing the resistance caused by the fibrous web. The determination of the permeability of fibrous porous media is a long standing, but still a challenging engineering problem. The effect of fluid inertia (Forchheimer term) on the permeability of fibrous media is a more complex problem, leading to the omission of the Forchheimer term in may calculations involving fibrous web even at very high air velocities $[\mathbf{2 2}, \mathbf{2 3}]$. In the present study, the effect of inertia is not included in the computation. The value of permeability $k$ is calculated from a model given by Mao and Russell [24, 25], which is based on drag theory and is specially developed for nonwoven fibrous web. According to the model, the permeability in the fibre plane is given by

$$
k=-\frac{1}{16} \frac{d_{\mathrm{f}}^{2}}{(1-\phi)}\left\{\frac{S T}{(T+S)}\right\}
$$


and perpendicular to the fibre plane is given by

$$
k_{z}=-\frac{1}{32} \frac{d_{\mathrm{f}}^{2}}{(1-\phi)} T
$$

In equations (3) and (4), $S=-\left[4(1-\phi)-(1-\phi)^{2}-\right.$ $3-2 \ln (1-\phi)]$ and $T=\ln (1-\phi)+\left\{1-(1-\phi)^{2}\right\} /$ $\left\{1-(1-\phi)^{2}\right\}$.

The porosity and permeability of the web undergo changes during the melting and bonding process, which is not quite understood yet, and are not included in the current stage of development of the mathematical model.

The averaged energy equation for the air and the porous matrix both in solid and in liquid states can be written as

$$
\begin{aligned}
\frac{\partial}{\partial t} & {\left[\phi \rho_{\mathrm{a}} h_{\mathrm{a}}+(1-\phi)\right.} \\
& \left.\times\left(\varepsilon\left(\gamma \rho_{\mathrm{l}} h_{1}+(1-\gamma) \rho_{\mathrm{s}} h_{\mathrm{s}}\right)+(1-\varepsilon) \rho_{\mathrm{c}} h_{\mathrm{c}}\right)\right] \\
& +\nabla \cdot\left(\rho_{\mathrm{a}} h_{\mathrm{a}} \bar{u}\right)=\nabla \cdot\left(k_{\mathrm{eff}} \nabla T\right)
\end{aligned}
$$

where $k_{\text {eff }}$ and $T$ are the effective thermal conductivity and temperature, respectively. The subscripts a refers to air, 1 the sheath fibre in liquid state, and $\mathrm{s}$ the sheath fibre in solid state, and $\mathrm{c}$ the core fibre (in solid state). For a pure fluid, phase change occurs at a fixed temperature, $T_{\mathrm{m}}$. At this temperature, the difference between the liquid and the solid enthalpies is equal to the latent heat of fusion, $\Delta h$. As the phases are assumed to be in thermal equilibrium, a volume element simultaneously occupied by liquid and solid will be theoretically at fusion temperature $T_{\mathrm{m}}$. In reality, however, a finite temperature gradient exists within a volume where the liquid and solid states coexist. Hence, it is assumed that the solid and liquid may exist simultaneously in a volume element if the mean temperature, $T$, is within a small interval, $2 \Delta T$, around the fusion temperature, $T_{\mathrm{m}}$. A typical variation of the liquid fraction, $\gamma$, with the mean temperature is shown in Fig. 3.

For a volume element undergoing phase change (i.e. $0<\gamma<1$ ), a change in the mean enthalpy of the fluid is due to a change in the liquid/solid mixture plus the contribution of the latent heat. A good approximation can be expressed as

$$
\begin{aligned}
d\left[\gamma \rho_{\mathrm{l}} h_{1}+(1-\gamma) \rho_{\mathrm{s}} h_{\mathrm{s}}\right] & =\left[\gamma \rho_{1} c_{1}+(1-\gamma) \rho_{\mathrm{s}} c_{\mathrm{s}}\right] \\
& =\mathrm{d} T+\rho_{\mathrm{l}} \Delta h \mathrm{~d} \gamma
\end{aligned}
$$

where $c_{\alpha}$ is the specific heat of constituent, $\alpha$. Substituting this into equation (5) and after simplifying results in

$$
\overline{\rho c} \frac{\partial T}{\partial t}+\rho_{\mathrm{a}} c_{\mathrm{a}} \nabla \cdot(\bar{u} T)=\nabla \cdot\left(k_{\mathrm{eff}} \nabla T\right)-(1-\phi) \varepsilon \rho_{\mathrm{l}} \Delta h \frac{\partial \gamma}{\partial t}
$$

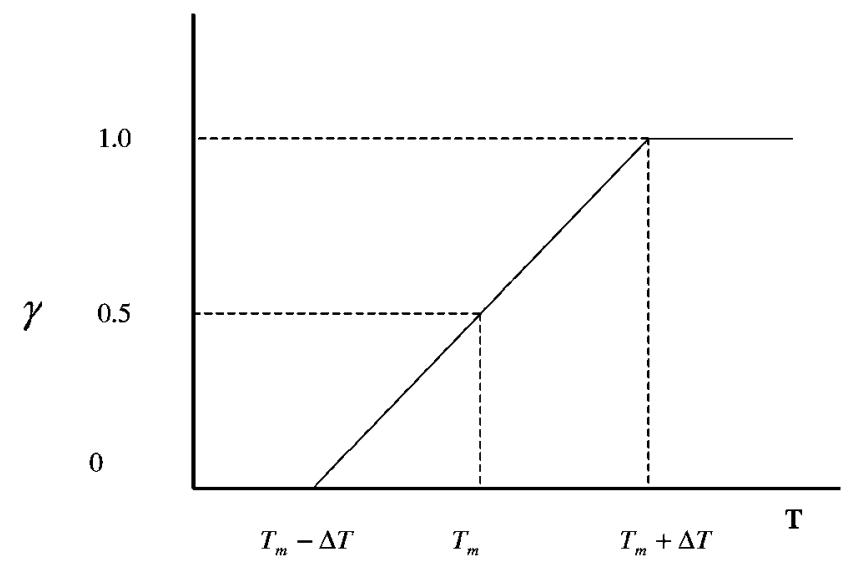

Fig. 3 Variation of melt fraction with temperature

where the mean thermal capacitance of the mixture, $\overline{\rho c}$ is defined as

$$
\begin{aligned}
\overline{\rho c}= & \phi \rho_{\mathrm{a}} c_{\mathrm{a}}+(1-\phi)\left[\varepsilon\left(\gamma \rho_{\mathrm{l}} c_{1}+(1-\gamma) \rho_{\mathrm{s}} c_{\mathrm{s}}\right)\right. \\
& \left.+(1-\varepsilon) \rho_{\mathrm{c}} c_{\mathrm{c}}\right]
\end{aligned}
$$

The effective thermal conductivity depends on general on the structure of the web as well as on the thermal conductivities and volume fraction of each constituent. As a first approximation, in the present study the effective thermal conductivity is given as a volumetric average

$$
k_{\mathrm{eff}}=\phi k_{\mathrm{a}}+(1-\phi)\left[\varepsilon\left(\gamma k_{1}+(1-\gamma) k_{\mathrm{s}}\right)+(1-\varepsilon) k_{\mathrm{c}}\right]
$$

In addition, the relationship describing $\gamma$ as a function of temperature is given by

$$
\gamma= \begin{cases}1 & \text { if } T>T_{\mathrm{m}}+\Delta T \\ 0 & \text { if } T<T_{\mathrm{m}}-\Delta T \\ \frac{T-T_{\mathrm{m}}+\Delta T}{2 \Delta T} & \text { if } T_{\mathrm{m}}-\Delta T<T<T_{\mathrm{m}}+\Delta T\end{cases}
$$

The solution of the energy equation for temperature is effectively an iterative process between the energy equation (7) and the liquid fraction equation (10).

\subsection{Solution procedure}

The FLUENT CFD software is used for the solution of the governing continuity and momentum equations together with a standard $k-\varepsilon$ turbulence model. The equations are solved on the basis of a porous media finite volume method and the velocity and pressure 
equations are coupled using the SIMPLE algorithm [26]. Though the default energy equation of the FLEUNT can calculate the heat transfer in porous media, it cannot model the melting of porous material and therefore was not solved. Instead, the energy equation given by equation (7) is solved through a user-defined scalar (UDS) routine. The presence of the mean thermal capacitance of the mixture, $\overline{\rho c}$, in the transient term makes the solution of the UDS equation difficult and further modification in the transient term was needed through a user-defined function (UDF). The default permeability model of FLUENT is not valid for nonwoven webs and therefore the model proposed by Mao and Russell [24] is incorporated through a UDF. The solution of the energy equation for temperature is an iterative process between the energy equation and the liquid fraction equation. Direct application of equation (10) to update the liquid fraction in the source term of the energy equation results in poor convergence. Therefore, the method proposed by Voller and Swaminathan [27] was utilized here. In this method, the liquid fraction at each iteration given by equation (10) is represented by a truncated Taylor series. The source term in the energy equation is then linearized, which leads to a robust, stable solution. Details of the model can be found in Voller and Swaminathan [27].

\section{PROBLEM CONSIDERATION}

\subsection{Computational domain}

A schematic drawing of a through-air bonding system is shown in Fig. 1. The nonwoven web is wrapped around a perforated rotating drum. The diameter of the drum is $1.4 \mathrm{~m}$ and the web has a wrap of $300^{\circ}$ and typical speed of the web is $150 \mathrm{~m} / \mathrm{min}$ (A. Watzl, 2003, personal communication). The air enters the web radially with a velocity in the range of $1.5-3 \mathrm{~m} / \mathrm{s}$. To simplify the development of the model, the CFD calculation was carried out on a $60^{\circ}$ sector of the drum and the drum was considered stationary. Figure 4 shows the computational domain and the boundary conditions. The computational domain was divided into the computational mesh with an average grid size of $1 \mathrm{~mm}$ in both radial and circumferential directions.

The web was assumed to be made of sheathcore type Celbond ${ }^{\circledR}$ KoSa bicomponent fibres of polyethylene (PE) sheath and polypropylene (PP) core. The fibre diameter was $15.15 \mu \mathrm{m}$ and the core diameter was $10.86 \mu \mathrm{m}$. The thermophysical properties of the fibres were supplied by the fibre manufacturer KoSa and are given in Table 1 .

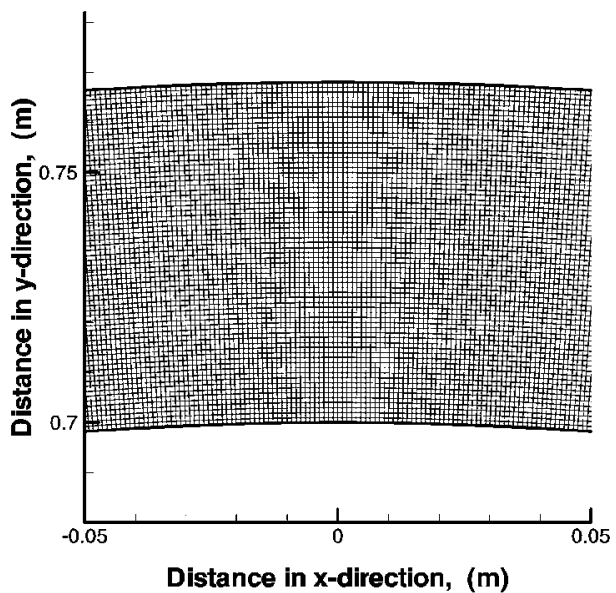

a) Computational grid

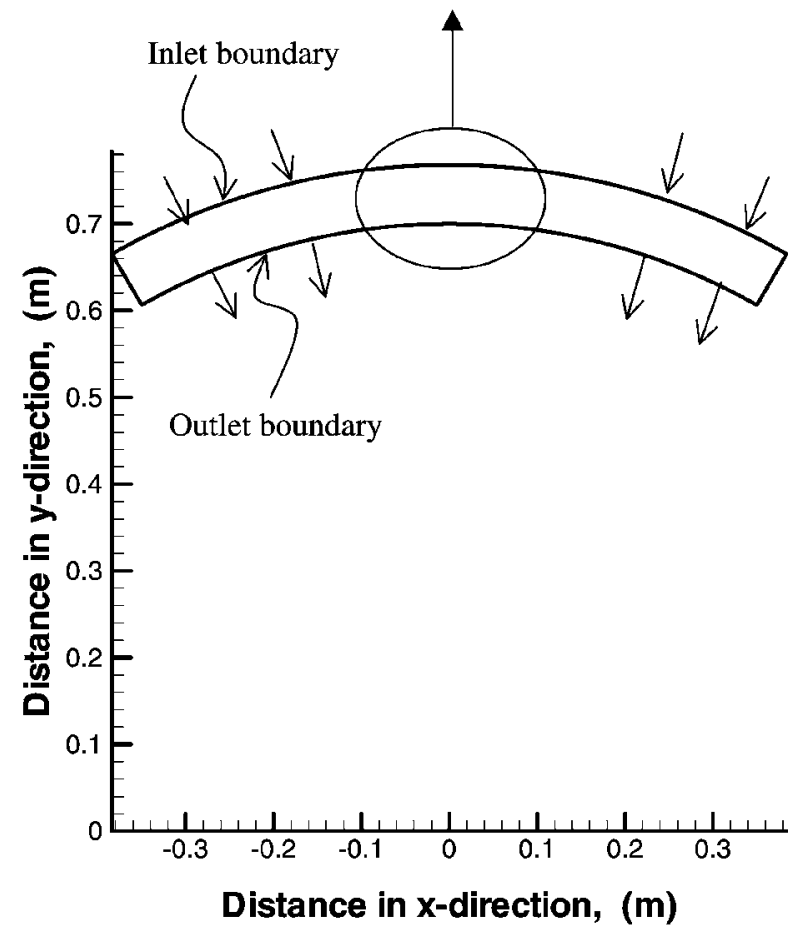

(b) Comptational domain and boundary conditions

Fig. 4 Simulations model: (a) close-up view of computational mesh and (b) computational domain and boundary conditions

\subsection{Boundary conditions}

A uniform velocity and temperature were specified at the inlet boundary. Pressure boundary condition was used at the outlet boundary. The inlet temperature was kept fixed at $140{ }^{\circ} \mathrm{C}$, and turbulence kinetic energy and eddy dissipation were set to $1 \mathrm{~m}^{2} / \mathrm{s}^{2}$ and $1 \mathrm{~m}^{2} / \mathrm{s}^{3}$, respectively. The transient solution was obtained with a fixed time step of $0.001 \mathrm{~s}$. The calculations were carried out for the air inlet velocity of $1.5,2.0,2.25,2.5$, and $3.0 \mathrm{~m} / \mathrm{s}$; the web porosity of 
Table 1 Properties of PE and PP used in the modelling

\begin{tabular}{lcc}
\hline Material & PE & PP \\
\hline$\rho\left(\mathrm{kg} / \mathrm{m}^{3}\right)$ & 950 & 900 \\
$C_{\mathrm{p}}(\mathrm{J} / \mathrm{kg} \mathrm{K})$ & 0.182 & 0.17 \\
$k(\mathrm{~W} / \mathrm{m} \mathrm{K})$ & 0.35 & 0.2 \\
Melting temperature $\left({ }^{\circ} \mathrm{C}\right)$ & 128 & 162 \\
Heat of fusion $(\mathrm{kJ} / \mathrm{mole})$ & 3.52 & \\
\hline
\end{tabular}

$0.5,0.7$, and 0.9 ; and the web thickness of $8.5,17,34$, and $68 \mathrm{~mm}$.

\section{RESULTS AND DISCUSSION}

The numerical errors associated with grid size are first assessed. The computation is carried out with an average grid size of $1 \mathrm{~mm}$ that resulted in $768 \times 68$ grids. Additional computations are carried out with average grid sizes of $0.5 \mathrm{~mm}(1536 \times 136$ grid) and $2 \mathrm{~mm}(384 \times 34$ grid). Figure 5 shows the radial velocity profile through the fibrous web. The velocity calculated using $384 \times 34$ grid size is somewhat smaller than the other two cases. The velocity computed using $768 \times 68$ and $1536 \times 136$ grid is indistinguishable. Therefore, it can be concluded that the $768 \times 68$ provides grid independent solution and this grid size allows the underlying mathematical model to be evaluated accurately.

Figure 6 shows the steady-state radial air velocity through the nonwoven web for three different porosities for the web thickness of $68 \mathrm{~mm}$ and inlet air velocity of $1.5 \mathrm{~m} / \mathrm{s}$. Simulation results show that the velocity field takes $<0.01 \mathrm{~s}$ to reach the steady-state

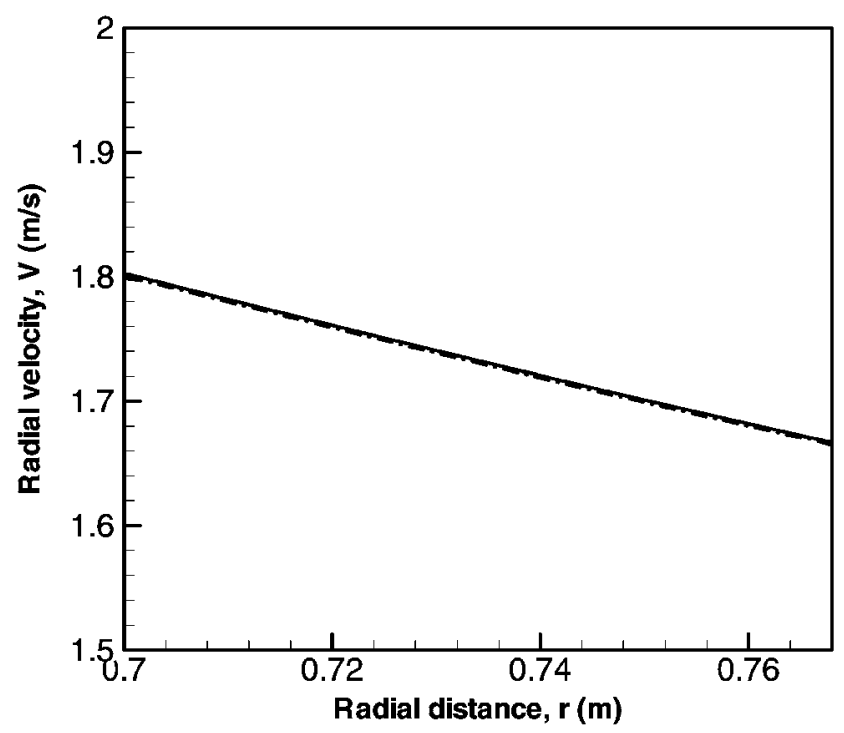

Fig. 5 Effect of grid size on the radial velocity profile at steady-state condition. ——, $768 \times 68$; - - - , $1536 \times 136 ;-\cdot-\cdot-, 384 \times 34$ condition. The porosity of the web has a significant effect on the airflow velocity through the web. Lowering the porosity, i.e. increasing fibres to volume ratio cause the overall air velocity through the web to increase significantly. The velocity increases in proportion to decrease in porosity inside the web, as less volume is available for airflow for lower porosity. The velocity also increases gradually from the inlet to the outlet, i.e. from the outer side of the web to the inner side, because of the reduction of flow area from the inlet towards the outlet due to reduction in radius. This is observed in all three porosity levels considered, but the change in velocity is highest for lowest porosity.

In practical situations, when the nonwoven web is wrapped around a drum, the web is compressed at the bottom and stretched at the top giving a possible rise to the porosity variation across the web thickness. Assuming the compression or expansion of fibres is negligible when compared with the compression or expansion of open pore spaces, a simple relationship between porosity and radius can be developed $\left(r \phi-r_{0} \phi_{0}=r-r_{0}\right.$; where $\phi_{0}$ is the porosity at the centre of the web $r_{0}$ ). This relationship gives a small variation of porosity across the web thickness from the base porosity of 0.9 for the case of $68 \mathrm{~mm}$ web. For example, the porosity at the inlet side of the web will be 0.905 and at the outlet side 0.895 . Therefore, the porosity of the web is assumed to be constant across the web, which simplifies the calculation.

Figure 7(a) gives the simulation results of temperature distribution inside the web and Fig. 7(b) shows the corresponding distribution of melt fraction of fibres. The predicted results are for the case of porosity 0.9 , air velocity $1.5 \mathrm{~m} / \mathrm{s}$, and web thickness

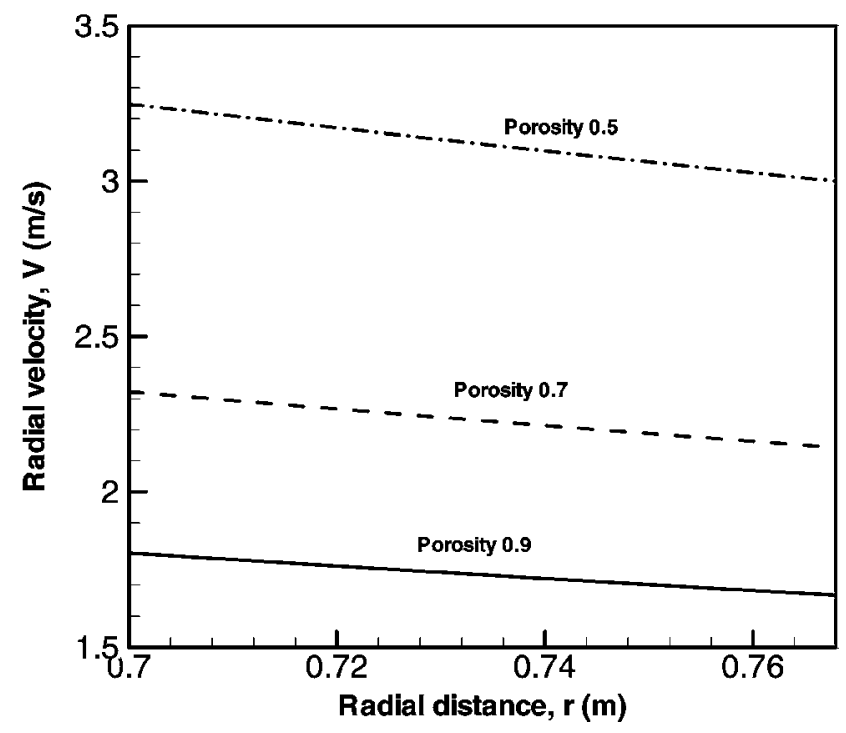

Fig. 6 Radial velocity profile at steady-state condition 

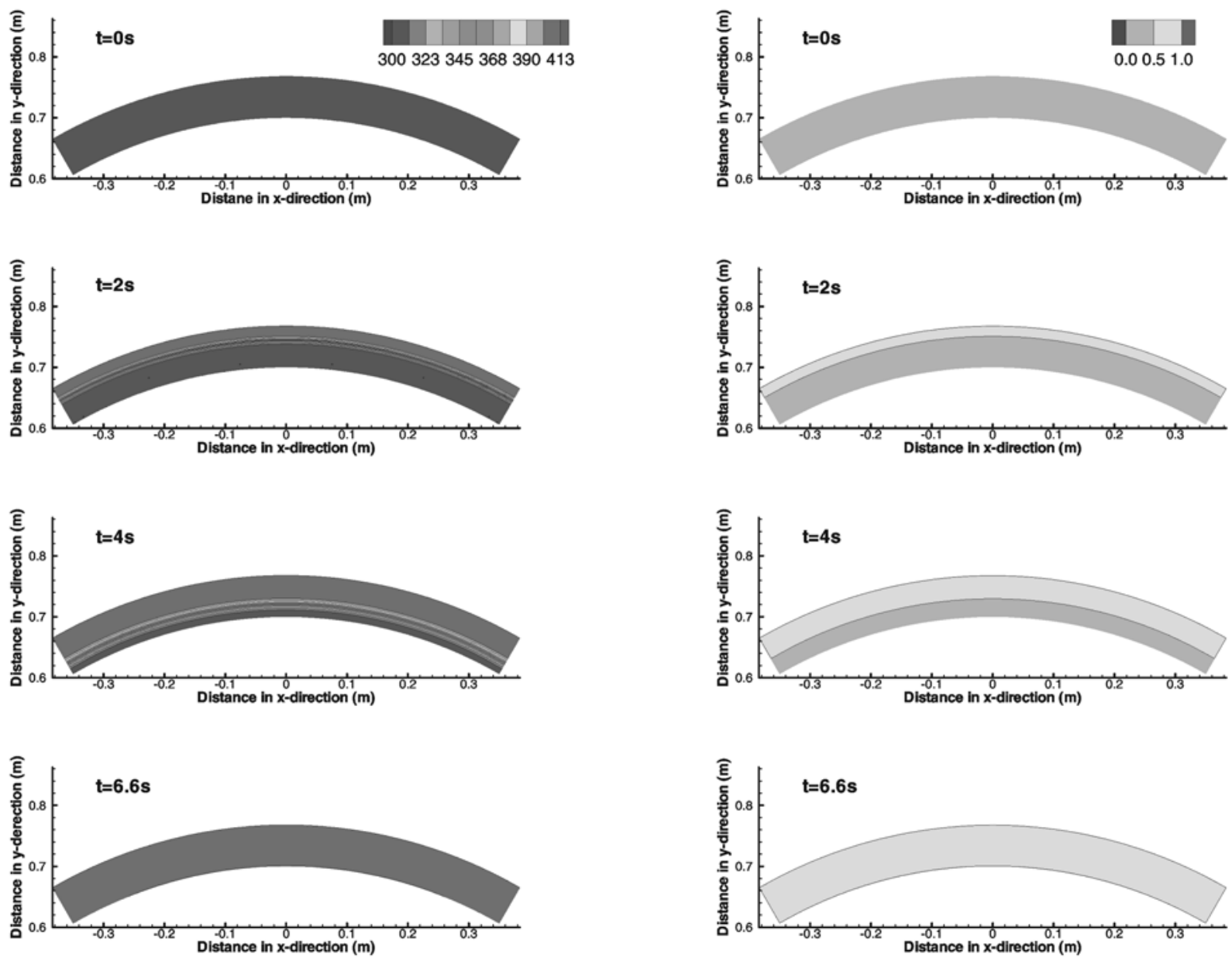

(a)

(b)

Fig. 7 Heating and melting progression through the web: (a) contours of temperature and (b) contours of melt fraction

$68 \mathrm{~mm}$. Hot air flows through the web heating the fibres above the melting temperature of fibres, so that the molten fibre polymer flows towards the contact point between fibres to form bond. During the heating process, three different zones of temperature field are observed inside the web. In the first zone, the web temperature is uniform and is equal to the air inlet temperature; in the intermediate zone, the temperature variation spreads over a small zone and inside this zone melting of fibres takes place; and in the third zone, the web temperature is uniform and is still at the initial temperature. Unlike the velocity field, it took $>6.6 \mathrm{~s}$ to heat and melt fibres throughout the web thickness and reach the steady-state condition.

As the fibres in the web melt in $6.6 \mathrm{~s}$, the simulation results at this time step were examined in more detail. Radial profiles of temperature and melt fraction for the porosity of $0.9,0.7$, and 0.5 are compared in Figs 8 and 9. The fibres at the inlet

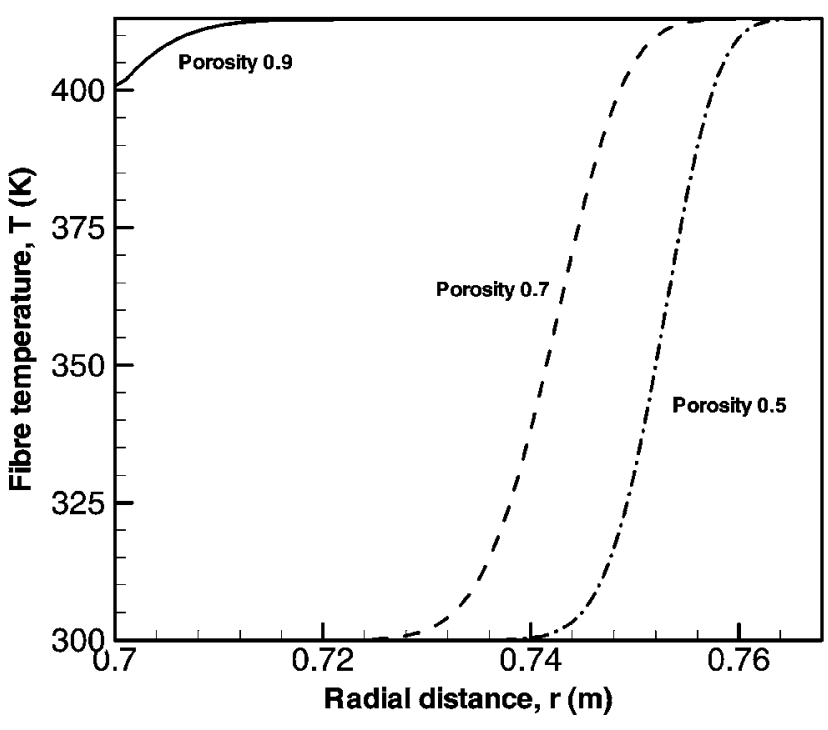

Fig. 8 Radial temperature profile at time $t=6.6 \mathrm{~s}$ 


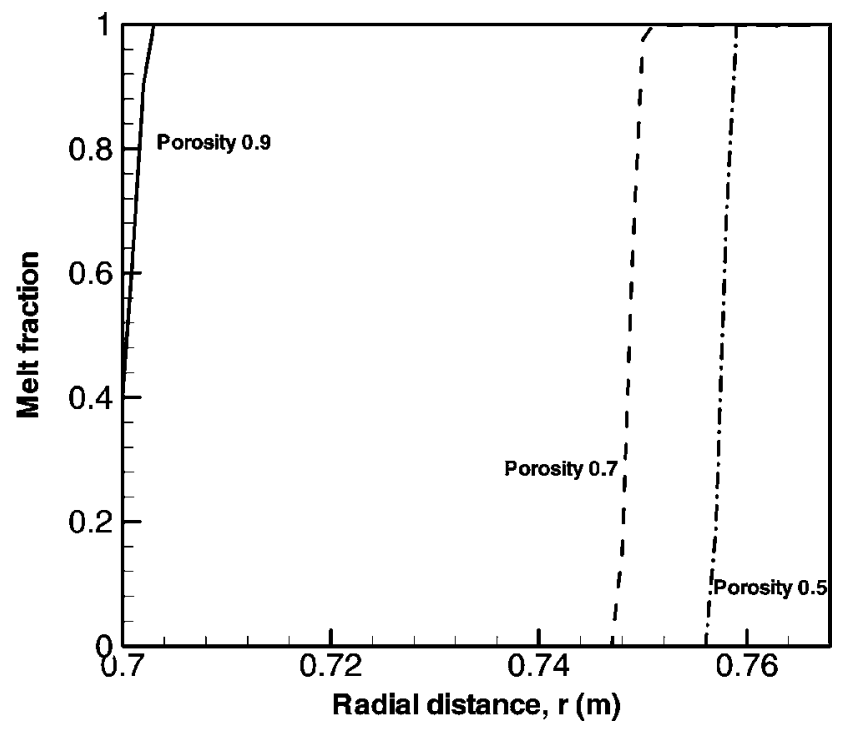

Fig. 9 Radial temperature profile at time $t=6.6 \mathrm{~s}$

side are heated to air inlet temperature long before the fibres at the outer edge. The temperature variation inside the web spreads over a small radius instead of the whole thickness of the web. This is because the heat transfer process is dominated by convection and melting, rather than the heat conduction through the web. From these figures, it can be seen that the effect of porosity is significant. Although the melting of fibres is complete in $6.6 \mathrm{~s}$ for the porosity of 0.9 , a small amount of fibres are melted for the porosity of 0.7 and 0.5 at this time.

Figure 10 shows the time required to melt fibres at different porosities for the case of web thickness of $68 \mathrm{~mm}$ and air velocity of $1.5 \mathrm{~m} / \mathrm{s}$. At low porosity,

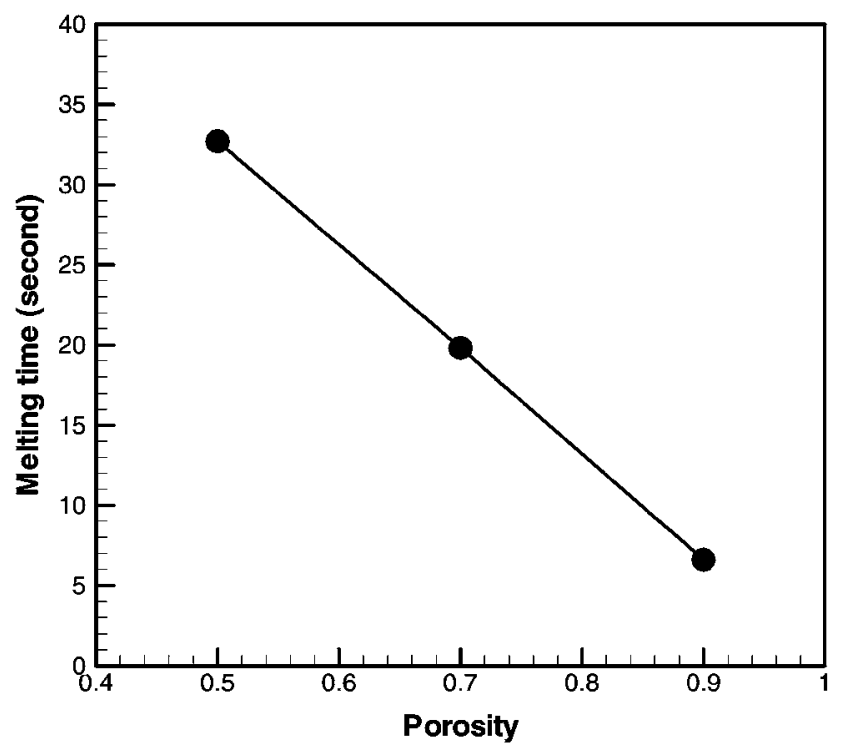

Fig. 10 Effect of porosity on the melting time of fibres

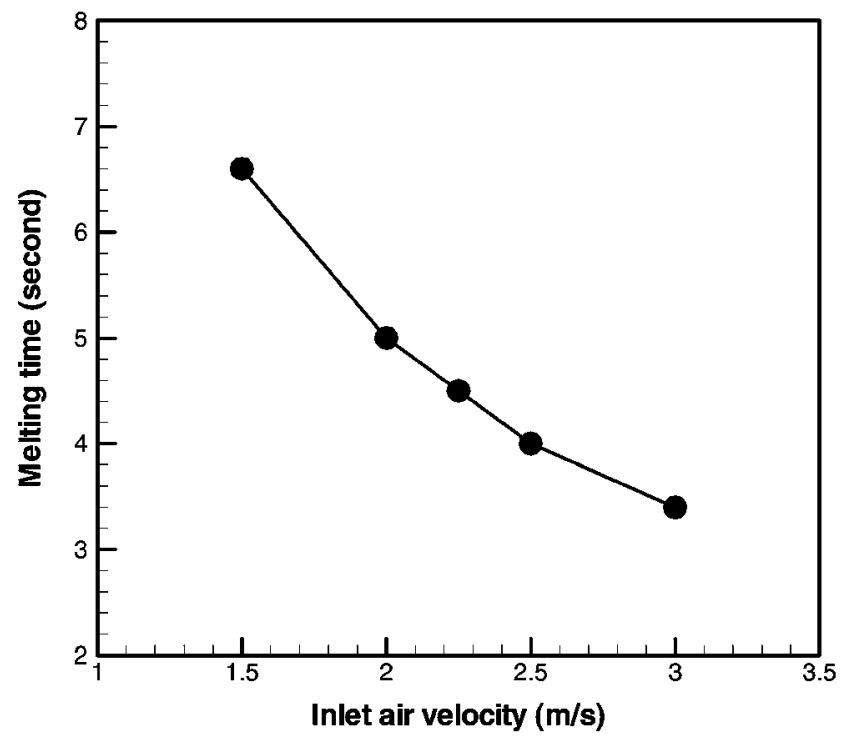

Fig. 11 Effect of air velocity on the melting time of fibres

the time required to melt fibres increases considerably. At lower porosity, the fibres are more concentred and the increased mass of fibres requires more heat and hence more time to be melted. Figure 11 shows the effect of air velocity on the time required to melt fibres for the case of $68 \mathrm{~mm}$ web thickness and porosity of 0.9 . The required time to melt fibres decreases with the increase of air velocity and shows a non-linear relationship. Figure 12 shows the effect of web thickness on the melting time for the case of air velocity of $1.5 \mathrm{~m} / \mathrm{s}$ and porosity of 0.9 . The melting

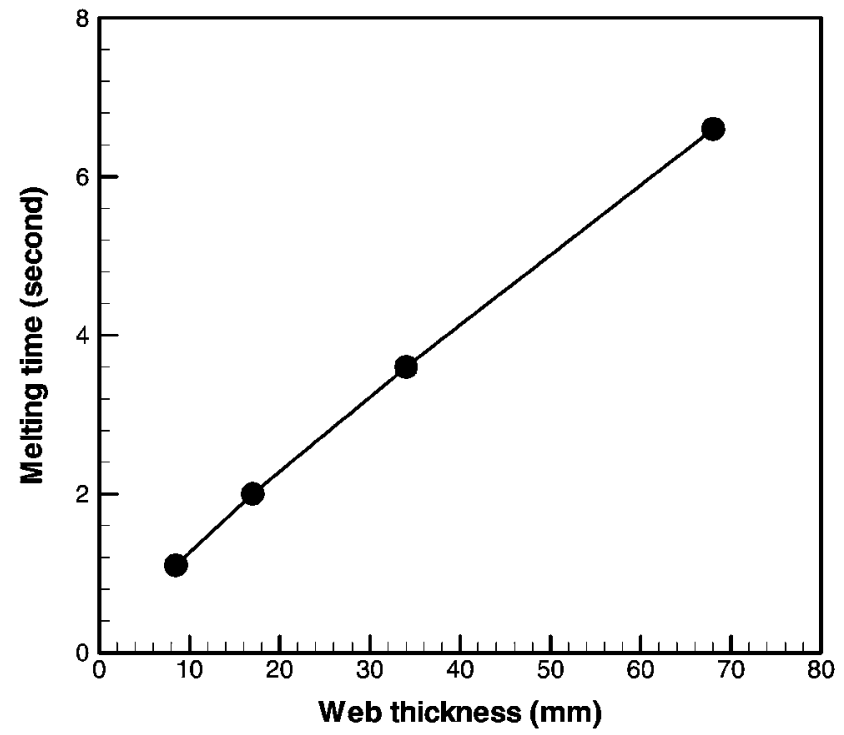

Fig. 12 Effect of web thickness on the melting time of fibres 
time increases linearly with the increase in web thickness.

\section{CONCLUSIONS}

A numerical model is developed to study the flow of air and heat transfer through fibrous webs such as those used in a through-air bonding process. The model is based on the porous media modelling concept. The main achievement of the current work is the development of a thermal energy equation, which considers the melting of the fibres. The model is applied for different process settings and web properties such as airflow velocity, web thickness, and porosity. The model provides a very important parameter, the time required to melt fibres throughout the web at different process conditions and web properties, which can be used potentially in the design of through-air bonding process.

\section{ACKNOWLEDGEMENT}

The research work is financially supported by Nonwovens Cooperative Research Center, Raleigh, NC, USA. The authors gratefully acknowledge their support.

\section{REFERENCES}

1 Warner, S. B. Thermal bonding of polypropylene fibres. Text. Res. J., 1989, 59(3), 51-159.

2 Wang, X. and Michielsen, S. Morphology gradients in thermal point bonded polypropylene. Text. Res. J., 2001, 71(6), 475-480.

3 Dharmadhikary, R. K., Gilmore, T. F., Davis, H. A., and Batra, S. K. Thermal bonding of nonwoven fabrics, 1995 (The Textile Institute, Manchester).

4 Randall, K. R. The influence of process variables on the properties of thermofusion bonded fabrics. In Proceedings of the Nonwoven Symposium, TAPPI, 1984.

5 Randall, K. R. Through air bonding of nonwoven fabrics using polypropylene binder fibres. In Proceedings of the 13th Annual Technical Symposium - Association of the Nonwovens Fabric Industry, Boston, MA, 1985, pp. 203-219.

6 Watzl, A. and Rückert, M. Industrial through air drying of nonwovens and paper-basic principles and applications. Dry. Technol., 1998, 16(6), 1027-1045.

7 Poirier, D., Guadagno, J., and Tourigny, C. Methods of evaluating hood drying rates. TAPPI J., 1996, 79(8), $183-188$.

8 Tourigny, C. and Ramaswamy, S. Methods of evaluating through air dryer drying rates. In Proceedings of the TAPPI Engineering Conference, Miami, FL, 1998, pp. 903-913.
9 Cui, Y., Ramaswamy, S., and Tourigny, C. Through air drying of tissue and towel grades. TAPPI J., 1999, 82(4), 203-209.

10 Ramaswamy, S. and Holm, R. A. Analysis of heat and mass transfer during drying paper/board. Dry. Technol., 1999, 17(1/2), 49-72.

11 Ramaswamy, S. and Holm, R. A. High intensity drying. Dry. Technol., 1999, 17(1/2), 73-95.

12 Lee, H. S., Carr, W. W., Beckham, H. B., and Leisen, J. A model of through - air drying of tufted textile materials. Int. J. Heat Mass Transfer, 2002, 45, 357-366.

13 Lee, H. S., Carr, W. W., Leisen, J., and Beckham, H. W. Through-air drying of unbacked tufted carpets. Text. Res. J., 2001, 71(7), 613-620.

14 Web site of FLUENT CFD software, available from http://www.fluent.com/.

15 Gong, R. H., Fang, C., and Porat, I. Single process production of 3D nonwoven shell structures - part 1: web forming system design using CFD modelling. Int. Nonwovens J., 2000, 9(4), 20-24.

16 Gong, R. H., Dong, Z., and Porat, I. Single process production of $3 \mathrm{D}$ nonwoven shell structures-part 2: CFD modelling of thermal bonding process. Int. Nonwovens J., 2001, 10(1), 24-28.

17 Kim, H. S., Ito, H., Kikutani, T., and Okui, N. Computational analysis on the thermal bonding behaviour of bicomponent fibres. J. Text. Inst., Part 1, 1999, 90(4), $508-525$.

18 Tafreshi, V. H. and Pourdeyhimi, B. Simulating the flow dynamics in hydroentangling nozzles: effect of cone angle and nozzle aspect ratio. Text. Res. J., 2003, 73(8), 700-704.

19 Tafreshi, H. V., Pourdeyhimi, B., Holmes, R., and Shiffler, D. Simulating and characterizing water flows inside hydroentangling orifices. Text. Res. J., 2003, 73(3), 256-262.

20 Mao, Z. and Goswami, B. C. Studies on the process of ultrasonic bonding of nonwovens: part 1 - theoretical analysis. Int. Nonwovens J., 2001, 10(2), 38-47.

21 Beckermann, C. and Viskanta, R. Natural convection solid/liquid phase change in porous media. Int. J. Heat Mass Transfer, 1988, 31(1), 35-46.

22 Barry, J. J. and Hill, R. W. Computational modelling of protective clothing. Int. Nonwoven J., 2003, 12(3), 25-34.

23 Bradean, R., Ingham, D. B., Wen, X., Russell, S. J., Pourmohammadi, A., and Harris, D. Modelling of an aerodynamics technique of forming web structures in textile industries: I. Turbulent air flow past filters, Math. Eng. Ind., 2001, 8(2), 137-160.

24 Mao, N. and Russell, S. J. Directional permeability in homogeneous nonwoven structures. Part 1: The relationship between directional permeability and fibre orientation. J. Text. Inst., 91(2), 235-243.

25 Mao, N. and Russell, S. J. Directional permeability in homogeneous nonwoven structures. Part 2: permeability in idealised structures. J. Text. Inst., 2000, 91(2), 244-258.

26 Versteeg, H. and Malalasekera, W. An introduction to computational fluid dynamics: the finite volume method, 1995 (Longman Scientific and Technical, New York). 
27 Voller, V. R. and Swaminathan, C. R. General sourcebased method for solidification phase change. Numer. Heat Transfer, Part B, 1991, 19, 175-189.

\section{APPENDIX}

\section{Notation}

c specific heat $(\mathrm{J} / \mathrm{kg} \mathrm{K})$

$d \quad$ diameter

$h \quad$ enthalpy $(\mathrm{J} / \mathrm{kg})$

$k$ permeability $\left(\mathrm{m}^{2}\right)$

$P \quad$ pressure $(\mathrm{Pa})$

$\mathrm{r} \quad$ radius $(\mathrm{m} / \mathrm{s})$

$T$ temperature (K)

$u \quad$ velocity $(\mathrm{m} / \mathrm{s})$

$x, y \quad$ coordinate location

$\begin{array}{ll}\Delta h & \text { heat of melting }(\mathrm{J} / \mathrm{kg}) \\ \varepsilon & \begin{array}{l}\text { volume fraction of sheath fibre in the } \\ \text { bicomponent fibre }\end{array} \\ \gamma & \text { fraction of melt of sheath fibre } \\ \phi & \text { volume fraction of air (porosity) } \\ \mu & \text { viscosity }(\mathrm{kg} / \mathrm{m} \mathrm{s}) \\ \rho & \text { density }\left(\mathrm{kg} / \mathrm{m}^{3}\right)\end{array}$

Subscripts

$\begin{array}{ll}\text { a } & \text { air } \\ \text { c } & \text { core fibre } \\ \text { eff } & \text { effective } \\ \text { f } & \text { fibre } \\ \text { l } & \text { sheath fibre in liquid state } \\ \text { m } & \text { melting } \\ \text { s } & \text { sheath fibre in solid state }\end{array}$

